\title{
VARIABILIDADE ESPACIAL DE ATRIBUTOS DE SOLOS EM UNIDADES DE MANEJO EM ÁREA PILOTO DE PRODUÇÃO INTEGRADA DE COCO $^{(1)}$
}

\author{
João Bosco Vasconcellos Gomes ${ }^{(2)}$, Edson Luis Bolfe ${ }^{(2)}$, Nilton \\ Curi $^{(3)}$, Humberto Rollemberg Fontes ${ }^{(2)}$, Antonio Carlos \\ Barreto $^{(2)}$ \& Robson Dantas Viana ${ }^{(4)}$
}

\begin{abstract}
RESUMO
O objetivo deste trabalho foi, inicialmente, acessar as variações espaciais dos solos de parcelas experimentais de produção integrada do coco por meio do mapeamento detalhado dos solos e da construção de mapas de contorno de atributos do solo. Foram feitas observações, medições e coleta de amostras em microtrincheiras e perfis de solo. $O$ teor de argila dos solos das microtrincheiras foi avaliado a campo pela sensação ao tato. Em todas as amostras foram realizadas análises físicas e químicas. Foram determinados granulometria (perfis), Al, Ca e Mg, acidez potencial, $\mathrm{K}$ e $\mathrm{Na}$, pH, $\mathrm{P}$ disponível e $\mathrm{C}$ orgânico. Nas amostras dos perfis, foram determinados $\mathrm{Fe}, \mathrm{Al}, \mathrm{Ti}, \mathrm{P}$ e Si pelo ataque sulfúrico. $\mathrm{O}$ Fe também foi determinado na fração argila, por extração com ditionito-citrato-bicarbonato de Na. Foi realizada difração de raios X da fração argila desferrificada. A construção de semivariogramas possibilitou a classificação e a comparação dos atributos do solo por meio do grau de dependência espacial destes. A elaboração dos mapas de contorno foi realizada pelo método interpolador de krigagem. A área mapeada corresponde a um topo amplo de tabuleiros costeiros, com uma depressão fechada no seu extremo sul. Do centro da depressão para fora dela seguem, em seqüência, Cambissolo Háplico textura argilosa, Latossolo Amarelo textura média/argilosa e Latossolo Amarelo textura média. Esses Latossolos são coesos em subsuperfície. Predominam atributos com elevado grau de heterogeneidade. Os valores médios de $\mathrm{P}, \mathrm{K}$ e $\mathrm{Ca}+\mathrm{Mg}$ estão influenciados por correções e adubações sistemáticas realizadas na área de plantio. Todas as variáveis analisadas apresentaram dependência espacial, expressa pelos modelos de semivariogramas. A análise da relação $C_{0} /\left(C_{0}+C_{1}\right)$ revelou um grau de dependência espacial, de todas as variáveis,
\end{abstract}

\footnotetext{
(1) Recebido para publicação em maio de 2007 e aprovado em outubro de 2008.

(2) Pesquisador da Embrapa Tabuleiros Costeiros. Av Beira-Mar 3250, CEP 49025-040 Aracaju (SE). E-mail: bosco@cpatc.embrapa.br; bolfe@ige.unicamp.br; humberto@cpatc.embrapa.br; barreto@cpatc.embrapa.br

(3) Professor Titular do Departamento de Ciência do Solo, Universidade Federal de Lavras - UFLA. Caixa Postal 30, CEP 37200000 Lavras (MG). Bolsista do CNPq. E-mail: niltcuri@ufla.br

(4) Analista da Embrapa Tabuleiros Costeiros. Av Beira-Mar 3250, CEP 49025-040 Aracaju (SE). E-mail: robson@cpatc.embrapa.br
} 
de moderado a forte. Os mapas de contorno detalharam diferenças que o mapa de solos já apontava para vários atributos, influenciados pela presença da depressão no extremo sul da área. Foram estabelecidas duas unidades de manejo para a área de estudo, as quais exigem práticas de manejo de água e solo diferenciadas.

Termos de indexação: Latossolo Amarelo Distrocoeso, geoestatística, planejamento de uso da terra.

\title{
SUMMARY: SOIL SPATIAL VARIATION AND PROPERTIES AS RELATED TO MANEGEMENT UNITS IN AN EXPERIMENTAL AREA OF INTEGRATED COCONUT PRODUCTION
}

\begin{abstract}
The objective of this work was to access spatial variations of soils from experimental plots for integrated coconut production based on the detailed mapping of soils and the construction of contour maps of soil properties. Observations and measurements were formed and samples collected in small trenches and soil profiles. The amount of soil clay from small trenches was evaluated in the field by finger touch feeling. Physical and chemical analyses were performed in all samples. Particle-size-distribution (profiles), Al, Ca and $\mathrm{Mg}$, potential acidity, $\mathrm{K}$ and $\mathrm{Na}, \mathrm{pH}$, available $\mathrm{P}$ and organic $C$ were determined. In samples from profiles $\mathrm{Fe}, \mathrm{Al}, \mathrm{Ti}, \mathrm{P}$ and $\mathrm{Si}$ were determined by sulphuric acid digestion. $\mathrm{Fe}$ was also analyzed in the clay fraction by $\mathrm{Na}$ dithionite-citrate-bicarbonate extraction. $X$ ray diffraction analysis was performed in the oxide-free clay fraction. The construction of semi-variograms made the classification possible, and the soil properties were compared based on the degree of spatial dependence. Contour maps were drawn using the kriging interpolator method. The mapped area is characterized by a broad summit of low coastal tablelands, with a closed depression in the far south of the area. From the depression center outwards we find, in sequence, a clayey Haplic Cambisol (Inceptsol), clay-laom Yellow Latosol (Oxisol) and a sandy-loam Yellow Latosol. These Oxisols have cohesive subsurface horizons. Attributes with high heterogeneity degree predominate. Average values of $P, K$ and $C a+M g$ are influenced by liming and systematic fertilization of the planting area. Spatial dependence was observed for all analyzed variables, expressed by the semi-variogram models. The $C_{0} /\left(C_{0}+C_{1}\right)$ ratio revealed a moderate to strong spatial dependence degree. The contour maps detailed differences for several attributes, also indicated by the soil map, as influenced by the depression in the far south. Two management units were discriminated for the study area, which require distinct water and soil management practices.
\end{abstract}

Index terms: Cohesive Yellow Latosol, Oxisol, geostatistics, land use planning.

\section{INTRODUÇÃO}

O Ministério da Agricultura, Pecuária e Abastecimento vem procurando construir uma filosofia de produção de frutíferas que alie qualidade de produto e sustentabilidade da exploração. Essa filosofia atende pelo nome de produção integrada (PI) de frutas (Andrigueto \& Kososki, 2002), que encontra na cultura da maçã seu estádio mais avançado no País. No Estado de Sergipe foram desenvolvidas ações da PI do coco (Cocos nucifera L.), concentradas, de forma experimental, em parcelas empresariais do perímetro irrigado do Platô de Neópolis.

Nessas parcelas existe a necessidade de um conhecimento detalhado sobre os solos em sua ambiência, possibilitando o paulatino desenvolvimento de técnicas de manejo (de convivência ou corretivas) condizentes com as limitações ambientais existentes e contribuindo para a maximização do retorno financeiro da atividade (Resende et al., 2002). Entretanto, a variabilidade dos solos dentro de glebas de plantio é negligenciada pela maioria das empresas agrícolas, que preferem, por motivo de simplificação, usar um mesmo conjunto de práticas de manejo do solo para o total do campo de produção, agindo assim como se este fosse homogêneo. Isso acontece mesmo para áreas em que estão disponíveis informações suficientes para definir manejos diferentes do solo. Esse comportamento, acontecendo de forma generalizada, pode acarretar sobre ou subintervenções em partes do campo de produção, incrementar os custos de manejo, decrescer o retorno econômico e aumentar a poluição de águas subterrâneas e superficiais (Castrignanò et al., 2000). 
O reconhecimento da importância da dependência espacial de atributos físicos, químicos e biológicos do solo e o uso de ferramentas de geoestatística estão multiplicando o número de estudos ligados ao tema em diferentes culturas agrícolas, inclusive em culturas semiperenes e perenes, como cana-de-açúcar, café, seringueira e citros (Souza et al., 1997; Corá et al., 2004; Roque et al., 2005; Silva et al., 2007; Berner et al., 2007). Esses estudos variam de centímetros para vários quilômetros de distância e permitem a construção de mapas de contorno das variáveis de interesse (Castrignanò et al., 2000; Cerri et al., 2004). Para a cultura do coco e paisagens de topo de tabuleiros costeiros inexistem pesquisas com a abordagem geoestatística.

Assim, este trabalho procurou acessar as variações espaciais dos solos de quatro parcelas experimentais da PI de coco (totalizando uma área de 35,98 ha) por meio do mapeamento detalhado dos solos e da construção de mapas de contorno de atributos físicos e químicos do solo, utilizando para isso métodos geoestatísticos, procurando-se entender a contribuição dessas variações para a tomada de decisões no âmbito da atividade produtiva.

\section{MATERIAL E MÉTODOS}

\section{Área de estudo}

A área de estudo está localizada no Perímetro Irrigado de Neópolis (Neópolis, SE), entre as coordenadas 8.853 .300 e $8.854 .200 \mathrm{~m} \mathrm{~N}$ e 749.200 e $750.100 \mathrm{~m}$ E (24L), na propriedade da empresa Frutese. O clima da região é do tipo As' (segundo Köppen), que corresponde ao clima tropical chuvoso com verão seco, em que a estação chuvosa se adianta para o outono, antes do inverno (abril a julho). A temperatura média anual é de $25,6^{\circ} \mathrm{C}$, com precipitação pluvial média anual de $1.181 \mathrm{~mm}$ (Posto Pacatuba). As paisagens compreendem topos planos a quase planos de elevações de tabuleiros costeiros (sedimentos da Formação Barreiras, da idade Terciária), com vegetação nativa transicionando entre Cerrado e floresta subcaducifólia (Embrapa, 1975; Sergipe, 1992).

São 35,98 ha plantados com coqueiro-anão com sete anos de idade, irrigados por microaspersão. $\mathrm{O}$ cultivo de coqueiro-anão é o principal produto do perímetro, com área plantada de 1.874 ha e produção de 41.500.000 frutos no ano de 2005. O manejo desses plantios inclui o uso de adubações, por vezes via fertirrigação, calagens e aplicação de pesticidas. As produtividades alcançadas no perímetro podem ser consideradas baixas para a cultura sob regime de irrigação, com os plantios apresentando problemas no manejo de água, nutrientes e fitossanidade.

\section{Mapeamento e coleta de amostras}

O mapeamento foi realizado por caminhamento da área, com a observação dos solos ocorrentes por meio de 93 microtrincheiras, complementadas com tradagens. A variabilidade de solos da área exigiu a descrição de quatro perfis de solo (perfis modais). Os solos e as unidades de mapeamento foram identificados conforme a nomenclatura do Sistema Brasileiro de Classificação de Solos (Embrapa, 2006).

As microtrincheiras foram localizadas nas entrelinhas do plantio e englobaram, além da classificação do solo, a descrição do relevo (declividade e posição na paisagem) e a observação de alguns atributos morfológicos nas profundidades de $0-20 \mathrm{~cm}$ (ou até o limite do horizonte A), 20-40 cm e 100-130 cm (cor, presença de mosqueado, textura avaliada pela sensação ao tato e a presença de camadas de impedimento até a profundidade de $150 \mathrm{~cm}$ ). Os perfis modais foram descritos em trincheiras, conforme Santos et al. (2005). O teor de argila dos solos de todas as microtrincheiras $(n=93)$ foi avaliado a campo pela sensação ao tato, conforme regras do quadro 1 . O intuito foi o de possibilitar a construção de mapa de contorno do teor de argila nas diferentes profundidades observadas. A coerência das avaliações foi checada pelos pontos das trincheiras, em que a textura foi realizada tanto pela sensação ao tato (no campo) como por análise de laboratório. Para aquelas amostras situadas nas classes de textura areia e franco-argiloarenosa, os resultados foram extremamente coerentes, com um desvio absoluto médio entre o resultado do laboratório e a textura pelo tato de $31,4 \mathrm{~g} \mathrm{~kg}^{-1} \mathrm{e}$ uma correlação linear de 0,84 entre os dois grupos de resultados $(\mathrm{p}<0,001, \mathrm{n}=14)$. Alguns fatores auxiliam essa boa correlação: o sedimento caulinítico e a estrutura pouco desenvolvida dos peds, o que facilita o manuseio das amostras para fins de exame da textura pela sensação ao tato.

Quadro 1. Correspondência utilizada entre a textura avaliada pela sensação ao tato e o teor de argila para o universo de solos estudados

\begin{tabular}{lc}
\hline Classe textural avaliada pelo tato & Teor de argila \\
& $\mathrm{g} \mathrm{kg}^{-1}$ \\
& 50 \\
Areia & 100 \\
Areia/areia franca & 110 \\
Areia franca/areia & 120 \\
Areia franca & 150 \\
Areia franca/franco-arenosa & 165 \\
Franco-arenosa baixa ${ }^{(1)}$ & 175 \\
Franco arenosa & 220 \\
Franco-argilo-arenosa baixa & 275 \\
Franco-argilo-arenosa & 300 \\
Franco-argilo-arenosa alta & $(2)$ \\
Franco-argilo-arenosa/argila arenosa & 320 \\
\hline
\end{tabular}

(1) Baixa: no limite inferior da classe, já transicionando para classe com menor teor de argila. ${ }^{(2)}$ Alta: no limite superior da classe, já transicionando para classe com maior teor de argila. 
Foram coletadas amostras nos horizontes genéticos dos quatro perfis modais. Em 26 das 93 microtrincheiras também foram coletadas amostras em três profundidades. As amostras de solo foram secas ao ar, destorroadas e passadas em peneiras de malha de $2 \mathrm{~mm}$, para obtenção da terra fina seca ao ar (TFSA).

\section{Análises de solos}

As análises físicas e químicas seguiram as recomendações da Embrapa (1997).

Na TFSA das amostras dos perfis modais e das microtrincheiras $(\mathrm{n}=26)$, foram determinados $\mathrm{Al}$, $\mathrm{Ca}$ e $\mathrm{Mg}$ trocáveis, acidez potencial $(\mathrm{Al}+\mathrm{H}), \mathrm{K}$ e Na trocáveis, $\mathrm{pH}$ em água, $\mathrm{P}$ disponível e $\mathrm{C}$ orgânico. Com os resultados obtidos nas análises do complexo sortivo, foram calculadas a soma de bases trocáveis (SB), a capacidade de troca catiônica total (CTC) e as saturações por bases (V) e por $\mathrm{Al}(\mathrm{m})$.

Apenas na TFSA dos perfis modais foram realizadas análise de granulometria e determinações de $\mathrm{Fe}, \mathrm{Al}$, $\mathrm{Ti}, \mathrm{P}$ e Si, após tratamento da TFSA com $\mathrm{H}_{2} \mathrm{SO}_{4}$ 1:1 (volume). As relações moleculares $\mathrm{SiO}_{2} / \mathrm{Al}_{2} \mathrm{O}_{3}$ (Ki), $\mathrm{SiO}_{2} /\left(\mathrm{Al}_{2} \mathrm{O}_{3}+\mathrm{Fe}_{2} \mathrm{O}_{3}\right)(\mathrm{Kr})$ e $\mathrm{Al}_{2} \mathrm{O}_{3} / \mathrm{Fe}_{2} \mathrm{O}_{3}$ foram calculadas.

Nos horizontes diagnósticos subsuperficiais dos perfis modais, foram separadas amostras de argila a partir da TFSA por sedimentação após dispersão com $\mathrm{NaOH} 1,0 \mathrm{~mol} \mathrm{~L}^{-1}$ (Embrapa, 1997). Nessas amostras de argila foi determinado o $\mathrm{Fe}$ (por absorção atômica) após extração com ditionito-citrato-bicarbonato de sódio (DCB) (Mehra \& Jackson, 1960). Na fração argila desferrificada com DCB (Mehra \& Jackson, 1960), foram realizadas análises de difração de raios X (DRX) e térmica diferencial (ATD). Lâminas orientadas foram confeccionadas para a DRX da fração argila desferrificada.

\section{Variabilidade espacial dos dados}

Foi analisada a variabilidade espacial do teor de argila avaliado pelo tato, $\mathrm{C}$ orgânico, $\mathrm{pH}$ em água, $\mathrm{P}$ disponível e várias determinações associadas ao complexo sortivo $(\mathrm{Ca}+\mathrm{Mg}, \mathrm{K}, \mathrm{Na}, \mathrm{Al}$, $\mathrm{SB}$ e CTC), utilizando-se técnicas de geoestatística (Vieira et al., 1983; Vieira, 2000). Todos os atributos foram analisados em três profundidades $(0$ a $20 \mathrm{~cm}$ ou até o limite do horizonte A, $20-40 \mathrm{~cm}$ e $100-130 \mathrm{~cm}$ ). A amostragem para o teor de argila avaliado pelo tato correspondeu à malha total do mapeamento de solos, ou seja, 93 microtrincheiras. Para os atributos químicos, a amostragem correspondeu a uma subpopulação de 26 microtrincheiras, das 93 totais (Figura 1). As coordenadas geográficas dos pontos amostrais foram locadas por meio de sistema de posicionamento global por satélite (GPS). Os dados de todos os atributos em cada ponto amostral foram associados a uma tabela que continha as coordenadas geográficas (x e y) dos referidos pontos. Os valores do coeficiente de determinação $\left(\mathrm{R}^{2}\right)$ e da soma dos quadrados dos resíduos (SQR) foram utilizados na seleção dos modelos de ajustes dos semivariogramas. A SQR é um parâmetro mais robusto do que a $\mathrm{R}^{2}$ e propicia a medida exata de quão bem o modelo se ajusta aos dados no caso da geoestatística (Robertson, 1998). Para a análise geoestatística, procedeu-se, então, à verificação da existência de dependência espacial por meio de semivariograma, estimado conforme a equação 1 :

$$
\gamma(h)=\frac{1}{2 N(h)} \sum_{i=1}^{N(h)}\left[Z\left(x_{i}\right)-Z\left(x_{i}+h\right)\right]^{2}
$$

em que N(h) representa o número de pares de valores medidos em [Z(xi), Z(xi + h)], separados por um vetor h. Para o estudo em questão, os valores de $Z$ foram os atributos do solo estudados, enquanto os valores de xi e $x i+h$ foram definidos de acordo com as posições das amostras no campo.

A análise da dependência espacial é baseada na suposição de que medições separadas por distâncias pequenas são mais semelhantes umas às outras que aquelas separadas por distâncias maiores. A distância-limite de dependência espacial, denominada alcance $\left(\mathrm{A}_{0}\right)$, indica que amostras localizadas a distâncias menores que o alcance são correlacionadas umas com as outras. O alcance depende do tamanho da área amostrada e da escala de observação realizada, sendo tanto maior quanto maior for o intervalo entre medidas (Trangmar et al., 1985). Neste estudo foi adotado o alcance prático, correspondente a $95 \%$ do patamar, e testados os modelos de semivariogramas: (a) esférico, $\gamma^{*}(\mathrm{~h})=\mathrm{C}_{0}+\mathrm{C}_{1}\left[1,5(\mathrm{~h} / \mathrm{a})-0,5(\mathrm{~h} / \mathrm{a})^{3}\right]$ para $(0<\mathrm{h}<\mathrm{a})$ e $\gamma^{*}(\mathrm{~h})=\mathrm{C}_{0}+\mathrm{C}_{1}$ para $\mathrm{h} \geq \mathrm{a}$; e (b) exponencial, $\gamma^{*}(\mathrm{~h})=\mathrm{C}_{0}+\mathrm{C}_{1}$ [1-exp (-3h/a) para $(0<\mathrm{h}<\mathrm{d})$, em que d é a distância máxima na qual o semivariograma é definido.

O ajuste matemático dos dados a partir do semivariograma possibilitou definir os seguintes parâmetros: efeito pepita $\left(\mathrm{C}_{0}\right)$; alcance da dependência espacial $\left(\mathrm{A}_{0}\right)$; patamar $\left(\mathrm{C}_{0}+\mathrm{C}_{1}\right)$; e a razão entre o efeito pepita e o patamar $\left[\left(\mathrm{C}_{0}\right) /\left(\mathrm{C}_{0}+\mathrm{C}_{1}\right)\right]$ - este último permitiu a classificação e a comparação entre os atributos do solo por meio do grau de dependência espacial. Utilizou-se esta razão para definir as diferentes classes de dependência espacial dos atributos do solo, conforme Cambardella et al. (1994): dependência espacial fraca $=\left(\mathrm{C}_{0}\right) /\left(\mathrm{C}_{0}+\mathrm{C}_{1}\right)>75 \%$; dependência espacial moderada $=\left(\mathrm{C}_{0}\right) /\left(\mathrm{C}_{0}+\mathrm{C}_{1}\right) \leq 75 \%$ e $>25 \%$; e dependência espacial forte $=\left(\mathrm{C}_{0}\right) /\left(\mathrm{C}_{0}+\mathrm{C}_{1}\right)$ $\leq 25 \%$. Assim, quanto menor essa relação, menor o valor relativo do efeito pepita e, conseqüentemente, mais bem arranjado espacialmente se encontra o atributo estudado.

Na elaboração dos mapas de contorno das variáveis estudadas, utilizou-se o programa Surfer 7.0 (Golden Software, 1999), que estima valores a partir do método interpolador geoestatístico de krigagem. Este interpolador utiliza a equação (2) (Thompson, 1992) e a equação (3) (Vieira, 2000) em sua seqüência de cálculos. 


$$
[\mathrm{A}]^{-1 *}[\mathrm{~b}]=[\lambda]
$$

em que $[\mathrm{A}]^{-1}$ é a matriz inversa de semivariância entre as localidades da vizinhança de um ponto, determinada pelo modelo de semivariograma com base nas distâncias euclidianas entre as localidades; [b] é a matriz de semivariância entre as localidades vizinhas (com a variável estimada) e o ponto para o qual a variável será interpolada, que também é determinado pelo modelo de semivariograma com base nas distâncias entre as localidades vizinhas e o ponto a ser interpolado; e [ $\lambda]$ é a matriz de pesos de krigagem.

$$
Z *\left(x_{0}\right)=\sum_{i=1}^{n} \lambda_{i} Z\left(x_{i}\right)
$$

em que $\mathrm{Z}\left(\mathrm{x}_{0}\right)$ é a variável interpolada; $\lambda_{\mathrm{i}}$ é o peso da iésima localidade vizinha; $\mathrm{Z}_{\mathrm{xi}}$ ) é o valor da variável para a i-ésima localidade; e n é o número de localidades vizinhas empregadas para interpolação do ponto.

Dessa forma, foram estimados os valores dos atributos para todas as posições não amostradas na área de estudo e, utilizando-se dos valores sem viés e com variância mínima obtidos pela krigagem, elaboraram-se os mapas de isolinhas (de contornos) para exame e interpretação da variabilidade dos atributos em questão.

\section{RESULTADOS E DISCUSSÃO}

\section{Caracterização dos solos}

A área mapeada corresponde a um topo amplo de tabuleiros costeiros, com uma depressão fechada no seu extremo sul. A partir dessa depressão é que se encontra a principal fonte de variabilidade de solos na área experimental. A presença de mosqueado em subsuperfície é comum em todos os solos da área, o que torna esse atributo de pouca validade na distinção dos ambientes locais. A textura e a cor ao longo do perfil dos solos são os atributos que melhor definem as qualidades de cada ponto de observação. Eles se relacionam com a posição na paisagem, o que na área associa-se à proximidade entre o ponto observado e o centro da depressão. Do centro da depressão para fora dela tem-se, em seqüência, Cambissolo Háplico Tb Distrófico (CXbd) gleissólico (subgrupo inexistente no sistema), Latossolo Amarelo Distrocoeso (LAdx) argissólico textura média/argilosa e LAdx argissólico textura média (Quadro 2 e Figura 1). Como inclusões, têm-se Argissolos Amarelos Distrocoesos.

O horizonte A dos CXbd são espessos e escuros (cor úmida 10YR 3/2), o que poderia ter caracterizado a presença de horizonte A chernozêmico ou A proeminente. Essa foi a impressão inicial no campo, não confirmada pelos baixos valores de $\mathrm{C}$ orgânico, menores que $6 \mathrm{~g} \mathrm{~kg}^{-1}$, mínimo exigido pelo critério do horizonte (Embrapa, 2006).

Esperava-se que os teores de $\mathrm{P}$ e de bases trocáveis fossem maiores, pelas sucessivas adubações recebidas na área de plantio. Embora o perfil 2, representativo da unidade de mapeamento LAdx2, seja eutrófico (inclusive os horizontes Bw do perfil), a unidade foi considerada apenas epieutrófica, pela média dos valores de V (saturação por bases) das amostras coletadas na área da unidade para construção dos mapas de contorno (Quadro 3 e Figura 5).

Quadro 2. Dados dos perfis de solos representativos da área mapeada, das parcelas experimentais da PIF

\begin{tabular}{|c|c|c|c|c|}
\hline Perfil & 1 & 2 & 3 & 4 \\
\hline Classificação & $\begin{array}{l}\text { Latossolo Amarelo } \\
\text { distrocoeso } \\
\text { argissólico }\end{array}$ & $\begin{array}{l}\text { Latossolo Amarelo } \\
\text { distrocoeso argissólico }\end{array}$ & $\begin{array}{l}\text { Cambissolo Háplico Tb } \\
\text { distrófico gleissólico }\end{array}$ & $\begin{array}{l}\text { Cambissolo Háplico Tb } \\
\text { distrófico gleissólico }\end{array}$ \\
\hline Tipo de horizonte A & moderado & moderado & moderado & moderado \\
\hline Situação & $\begin{array}{l}\text { Topo plano de } \\
\text { tabuleiro }\end{array}$ & Topo plano de tabuleiro & $\begin{array}{l}\text { Terço superior de encosta } \\
\text { associado à depressão suave }\end{array}$ & $\begin{array}{l}\text { Fundo de depressão } \\
\text { suave }\end{array}$ \\
\hline Drenagem & Bem & moderadamente & $\begin{array}{l}\text { moderada a } \\
\text { imperfeitamente }\end{array}$ & Imperfeitamente \\
\hline Textura horizonte A & média & média & média & média \\
\hline Textura horizonte B & média & argilosa & argilosa & argilosa \\
\hline Cor horizonte B & 10YR 6/4 & $10 \mathrm{YR} 5 / 3$ a $7,5 \mathrm{YR} 6 / 6$ & 10YR $6 / 3$ & 10YR $4 / 2$ a $7 / 1$ \\
\hline $\begin{array}{l}\text { Mosqueado e outras } \\
\text { feições }\end{array}$ & $\begin{array}{l}\text { Abundante entre } 107 \\
\text { e } 121 \mathrm{~cm}\end{array}$ & $\begin{array}{l}\text { Plintitização a partir de } \\
190 \mathrm{~cm}\end{array}$ & $\begin{array}{l}\text { Cores gleicas a partir de } \\
120 \mathrm{~cm}\end{array}$ & $\begin{array}{l}\text { Cores gleicas a partir de } \\
135 \mathrm{~cm}\end{array}$ \\
\hline $\begin{array}{l}\text { Saturação por } \\
\text { bases em superfície }\end{array}$ & eutrófico & eutrófico & eutrófico & eutrófico \\
\hline
\end{tabular}
coco, Frutese, Platô de Neópolis, SE 


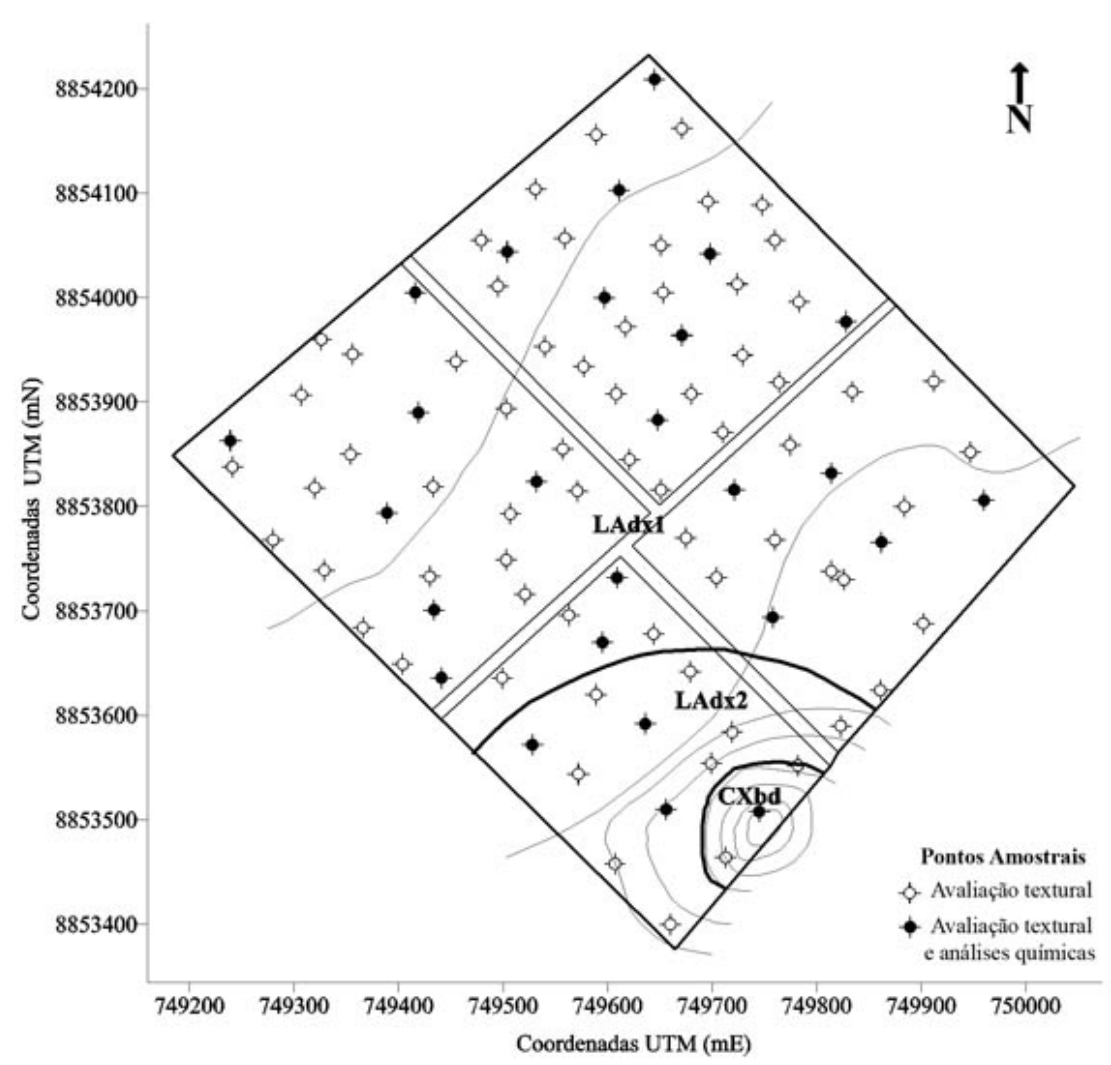

Figura 1. Mapa de solos das parcelas experimentais e pontos amostrais da PI coco, Frutese, Platô de Neópolis, SE. Legenda: LAdx1: Latossolo Amarelo Distrocoeso argissólico A moderado textura média cerrado/ floresta tropical subcaducifólia relevo plano $\left(0-1 \mathrm{~cm} \mathrm{~m}^{-1}\right.$ de declividade) epieutrófico; LAdx2: Latossolo Amarelo Distrocoeso argissólico A moderado textura média/argilosa cerrado/floresta tropical subcaducifólia relevo plano $\left(0-1 \mathrm{~cm} \mathrm{~m}^{-1}\right.$ de declividade) epieutrófico; CXbd: Cambissolo Háplico Tb distrófico gleissólico A moderado textura média/argilosa cerrado/floresta tropical subcaducifólia relevo plano a suave ondulado (1-4 $\mathrm{cm} \mathrm{m}^{-1}$ de declividade) epieutrófico, endoálico.

Todos os solos são originados de sedimentos da Formação Barreiras. Os valores da relação $\mathrm{Ct} / \mathrm{Gb}$ (ATD) e os DRX confirmam a mineralogia caulinítica desses solos (Quadro 3 e Figura 2). A expressão da coesão em subsuperfície - característica desses solos - é atenuada pela irrigação. Ker (1998) apontou para a ausência do caráter coeso nos LA de Manaus por razão semelhante - no caso, a ausência de déficits hídricos na região. Dessa forma, o terceiro nível da classificação dos LA, Grande Grupo, foi definido por correlação com áreas de sequeiro, que expressam coesão para solos semelhantes.

\section{Análises estatísticas clássicas}

A maioria dos atributos apresentou elevado grau de heterogeneidade, com muitos coeficientes de variação elevados (Quadro 4). O pH é uma exceção esperada, por variar dentro de um intervalo muito estreito. Parte das variáveis não apresentou distribuição normal, não sendo essa uma exigência da geoestatística (Corá et al., 2006). Três valores discrepantes sobressaíram nas variáveis $\mathrm{Al}, \mathrm{P}$ disponível e SB (Al em uma amostra de 0-20 cm, P disponível em uma amostra de 40-60 cm e SB em uma amostra de 100-130 cm), acarretando uma distribuição dos dados mais longe da normalidade para essas variáveis nas referidas profundidades. As diferenças entre as três profundidades amostradas são marcantes e esperadas, principalmente das amostras superficiais, para as outras duas profundidades. Os valores médios de $\mathrm{P}, \mathrm{K}$ e Ca + Mg estão claramente influenciados por correções e adubações sistemáticas realizadas na área de plantio (coberturas e fertirrigação). O único atributo a aumentar o teor até a profundidade de $100-130 \mathrm{~cm}$ foi o $\mathrm{Al}$, pela dificuldade de sua correção em profundidade. Dessa forma, o $\mathrm{Al}$ acumula em profundidade e os horizontes superficiais estão basicamente isentos deste - uma conseqüência das correções pelo uso do calcário. O teor de $\mathrm{Na}$ aumentou da superfície para a profundidade de 40-60 cm, em razão de sua elevada solubilidade (Miller \& Donahue, 1992). É provável que nessa profundidade do solo um maior teor de argila tenha possibilitado sua imobilização, mesmo considerando a relativa facilidade de lixiviação em profundidade do elemento para camadas mais profundas (Castrignanò 
Quadro 3. Atributos de horizontes selecionados de perfis de solos das parcelas experimentais da PIF coco, Frutese, Platô de Neópolis, SE

\begin{tabular}{|c|c|c|c|c|c|c|c|c|c|c|}
\hline Horizonte & Profundidade & Argila & C orgânico & $\mathbf{P}$ & $\mathbf{V}$ & $\mathbf{m}$ & $\mathrm{Fe}_{2} \mathrm{O}_{3}^{(1)}$ & $\mathbf{F e}_{\mathrm{d}}{ }^{(1)}$ & $\mathbf{K i}^{(1)}$ & $\mathrm{Ct} /(\mathrm{Ct}+\mathrm{Gb})^{(1)}$ \\
\hline & $\mathrm{cm}$ & $\mathrm{g} \mathrm{kg}^{-1}$ & dag kg ${ }^{-1}$ & $\mathrm{mg} \mathrm{dm^{-3 }}$ & \multicolumn{2}{|c|}{$\%$} & $\mathrm{~g} \mathrm{~kg}^{-1}$ & $\mathrm{mg} \mathrm{kg}^{-1}$ & & \\
\hline \multicolumn{11}{|c|}{ Perfil 1} \\
\hline Ap1 & $0-10$ & 100 & 0,64 & 11,5 & 86 & 0 & 6,0 & - & 1,81 & - \\
\hline Ap2 & $10-36$ & 160 & 0,35 & 1,2 & 76 & 0 & 12,0 & - & 1,59 & - \\
\hline Bw2 & $107-121(132)$ & 280 & 0,17 & 0,4 & 35 & 28 & 15,1 & 11,56 & 1,98 & 0,95 \\
\hline Bw3 & $121(132)-154$ & 340 & 0,17 & 0,4 & 45 & 32 & 20,1 & 14,92 & 1,84 & 0,97 \\
\hline \multicolumn{11}{|c|}{ Perfil 2} \\
\hline Ap1 & $0-7$ & 220 & 1,22 & 12,8 & 82 & 0 & 13,1 & - & 1,64 & - \\
\hline Ap2 & $7-35$ & 300 & 0,58 & 1,4 & 64 & 5 & 17,1 & - & 1,93 & - \\
\hline Bw1 & $56-104$ & 440 & 0,17 & 0,4 & 56 & 21 & 27,2 & 20,39 & 1,91 & 0,97 \\
\hline Bw2 & $104-140$ & 480 & 0,17 & 0,1 & 57 & 17 & 31,2 & 21,48 & 1,96 & 0,96 \\
\hline \multicolumn{11}{|c|}{ Perfil 3} \\
\hline Ap1 & $0-17$ & 200 & 0,58 & 8,5 & 72 & 0 & 10,1 & - & 1,91 & - \\
\hline $\mathrm{A} 2$ & $17-35$ & 300 & 0,58 & 2,0 & 38 & 29 & 12,1 & - & 1,90 & - \\
\hline $\mathrm{AB}$ & $35-76$ & 380 & 0,35 & 0,9 & 17 & 61 & 15,2 & - & 1,76 & - \\
\hline $\mathrm{BA}$ & $76-105(127)$ & 360 & 0,17 & 0,4 & 20 & 63 & 15,1 & - & 1,90 & - \\
\hline $\mathrm{Bi}$ & $105(127)-120(183)$ & 360 & 0,17 & 0,4 & 22 & 61 & 15,1 & 7,91 & 1,84 & 0,97 \\
\hline Big & $120(183)-200+$ & 520 & 0,17 & 0,4 & 22 & 65 & 18,2 & 2,30 & 1,88 & 0,97 \\
\hline \multicolumn{11}{|c|}{ Perfil 4} \\
\hline Ap1 & $0-30$ & 220 & 0,52 & 3,4 & 64 & 5 & 8,0 & - & 1,78 & - \\
\hline Ap2 & $30-105$ & 320 & 0,35 & 0,9 & 17 & 62 & 10,1 & - & 1,58 & - \\
\hline $\mathrm{Bi} 2$ & $135-177(183)$ & 380 & 0,23 & 0,9 & 14 & 73 & 13,1 & 3,09 & 1,93 & 0,98 \\
\hline Big & $177(183)-200+$ & 440 & 0,17 & 0,4 & 22 & 67 & 11,1 & 1,00 & 1,11 & 0,96 \\
\hline
\end{tabular}

${ }^{(1)} \mathrm{Fe}_{2} \mathrm{O}_{3}$ : ataque sulfúrico; $\mathrm{Fe}_{\mathrm{d}}$ : ditionito-citrato-bicarbonato de $\mathrm{Na}$; Ki: relação molecular $\mathrm{SiO}_{2} / \mathrm{Al}_{2} \mathrm{O}_{3} ; \mathrm{Ct} / \mathrm{Gb}$ : relação caulinita/ gibbsita calculada por ATD.

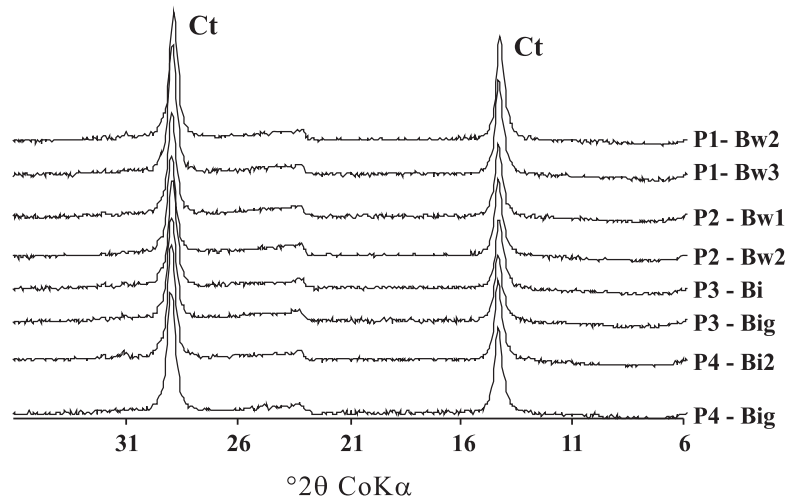

Figura 2 Difratogramas de raios $\mathrm{X}$ de amostras da fração argila desferrificada de horizontes subsuperficiais de perfis de solo das parcelas experimentais da PIF coco, Frutese, Platô de Neópolis, SE. Legenda: Ct: caulinita; P1: perfil 1 (LAdx textura média); P2: perfil 2 (LAdx textura média/argilosa); P3: perfil 3 (CXbd textura média/argilosa); $\mathrm{P} 4$ : perfil 4 (CXbd textura média/argilosa).

et al., 2000), em consonância com os baixos valores de permeabilidade registrados na subsuperfície desses solos.

\section{Análises dos variogramas}

Para cada atributo estudado, ajustaram-se os modelos esférico e exponencial pelo método da tentativa e erro, analisando-se a sensibilidade, sendo adotado para este estudo o modelo esférico, o qual apresentou melhores parâmetros no estudo de erros (Vieira et al., 1983), resultado verossímel em se tratando de atributos do solo (Souza et al., 1997). No quadro 5 são apresentados os estimadores dos parâmetros dos semivariogramas e os coeficientes de determinação dos modelos ajustados. Os semivariogramas direcionais foram avaliados e, como não foi detectada anisotropia (variabilidade diferenciada segundo a direção tomada), utilizaram-se os semivariogramas médios isotrópicos. Todas as variáveis analisadas apresentaram alguma dependência espacial nas diferentes profundidades $(0-$ 20, 40-60 e 100-130 cm), expressa pelos modelos de semivariogramas.

Os atributos estudados apresentaram alcances que variaram de 119 a $367 \mathrm{~m}$ (Quadro 5). Os resultados apontam para uma grande heterogeneidade da adubação na área, sobretudo na observação dos valores de $\mathrm{A}_{0}$ da camada superficial. Esta camada, como seria esperado, apresenta, em média, menores valores de alcance de dependência espacial. Corá et al. (2004) discutiram o assunto trabalhando com Latossolos Vermelhos em Jaboticabal, SP. Esses autores comentaram o maior grau de descontinuidade da camada mais profunda desses Latossolos em relação à camada superficial, o inverso do observado aqui, explicando o ocorrido pelo longo histórico (mais de 30 anos com cana-de-açúcar) da área estudada, 
Quadro 4. Estatística básica e parâmetros de normalidade de variáveis de materiais de solos avaliados ou coletados em microtrincheiras das parcelas experimentais da PIF coco, Frutese, Platô de Neópolis, SE

\begin{tabular}{|c|c|c|c|c|c|c|c|c|}
\hline \multirow{2}{*}{ Variável } & \multirow{2}{*}{ Unidade } & \multirow{2}{*}{ Média } & \multirow{2}{*}{ Mínimo } & \multirow{2}{*}{ Máximo } & \multirow{2}{*}{ Desvio-padrão } & \multicolumn{3}{|c|}{ Coeficientes } \\
\hline & & & & & & Variação (\%) & Assimetria & Curtose \\
\hline \multicolumn{9}{|c|}{ Amostras superficiais (0-20 cm ou limite do horizonte A, quando este é mais estreito que o limite dado) } \\
\hline Argila & $\%$ & 12 & 5 & 32 & 7,63 & 58,20 & 0,98 & 0,06 \\
\hline C orgânico & $\mathrm{g} \mathrm{kg}^{-1}$ & 9,10 & 2,32 & 20,88 & 4,63 & 50,88 & 0,62 & 0,01 \\
\hline pH água & - & 6,42 & 5,40 & 7,00 & 0,40 & 6,23 & $-0,85$ & 0,56 \\
\hline $\mathrm{P}$ & $\mathrm{mg} \mathrm{kg}^{-1}$ & 15,85 & 2,90 & 61,90 & 14,33 & 90,41 & 1,66 & 2,94 \\
\hline $\mathrm{Ca}+\mathrm{Mg}$ & $\mathrm{cmol}_{\mathrm{c}} \mathrm{kg}^{-1}$ & 2,45 & 1,27 & 4,19 & 0,77 & 31,43 & 0,52 & $-0,53$ \\
\hline $\mathrm{K}$ & $\mathrm{cmol}_{\mathrm{c}} \mathrm{kg}^{-1}$ & 0,15 & 0,06 & 0,56 & 0,11 & 73,33 & 2,02 & 4,93 \\
\hline $\mathrm{Na}$ & $\mathrm{cmolc} \mathrm{kg}^{-1}$ & 0,04 & 0,02 & 0,12 & 0,03 & 75,00 & 1,76 & 3,94 \\
\hline $\mathrm{Al}$ & $\mathrm{cmolc} \mathrm{kg}^{-1}$ & 0,02 & 0,00 & 0,20 & 0,05 & 250,00 & 3,22 & 10,48 \\
\hline SB & $\mathrm{cmol}_{\mathrm{c}} \mathrm{kg}^{-1}$ & 2,64 & 1,41 & 4,41 & 0,82 & 31,06 & 0,51 & $-0,59$ \\
\hline CTC & $\mathrm{cmol}_{\mathrm{c}} \mathrm{kg}^{-1}$ & 3,95 & 2,43 & 5,84 & 1,12 & 28,35 & 0,32 & $-1,17$ \\
\hline \multicolumn{9}{|c|}{ Amostras de $40-60 \mathrm{~cm}$} \\
\hline Argila & $\%$ & 29 & 22 & 55 & 5,90 & 34,76 & 2,58 & 6,35 \\
\hline C orgânico & $\mathrm{g} \mathrm{kg}^{-1}$ & 5,20 & 0,58 & 12,76 & 3,21 & 61,73 & 0,70 & $-0,09$ \\
\hline pH água & - & 5,57 & 4,30 & 6,90 & 0,61 & 11,01 & 0,35 & $-0,14$ \\
\hline $\mathrm{P}$ & $\mathrm{mg} \mathrm{kg}^{-1}$ & 1,13 & 0,10 & 5,40 & 1,02 & 89,95 & 3,04 & 12,35 \\
\hline $\mathrm{Ca}+\mathrm{Mg}$ & $\mathrm{cmol}_{\mathrm{c}} \mathrm{kg}^{-1}$ & 0,64 & 0,23 & 1,67 & 0,34 & 54,07 & 1,67 & 3,30 \\
\hline $\mathrm{K}$ & $\mathrm{cmol}_{\mathrm{c}} \mathrm{kg}^{-1}$ & 0,08 & 0,02 & 0,23 & 0,05 & 62,13 & 1,32 & 2,23 \\
\hline $\mathrm{Na}$ & $\mathrm{cmol}_{\mathrm{c}} \mathrm{kg}^{-1}$ & 0,05 & 0,02 & 0,09 & 0,02 & 37,88 & 1,40 & 2,69 \\
\hline $\mathrm{Al}$ & $\mathrm{cmol}_{\mathrm{c}} \mathrm{kg}^{-1}$ & 0,54 & 0,00 & 1,72 & 0,41 & 75,76 & 1,67 & 3,09 \\
\hline SB & $\mathrm{cmol}_{\mathrm{c}} \mathrm{kg}^{-1}$ & 0,76 & 0,35 & 1,83 & 0,35 & 46,46 & 1,64 & 3,16 \\
\hline $\mathrm{CTC}$ & $\mathrm{cmol}_{\mathrm{c}} \mathrm{kg}^{-1}$ & 3,18 & 1,09 & 6,63 & 1,29 & 40,69 & 1,40 & 1,90 \\
\hline \multicolumn{9}{|c|}{ Amostras de $100-130 \mathrm{~cm}$} \\
\hline Argila & $\%$ & 31 & 27,5 & 63 & 7,92 & 62,74 & 2,56 & 5,52 \\
\hline C orgânico & $\mathrm{g} \mathrm{kg}^{-1}$ & 3,37 & 0,58 & 9,86 & 2,18 & 64,61 & 0,97 & 1,82 \\
\hline pH água & - & 5,19 & 4,30 & 6,40 & 0,46 & 8,88 & 0,56 & 0,68 \\
\hline $\mathrm{P}$ & $\mathrm{mg} \mathrm{kg}^{-1}$ & 0,32 & 0,10 & 1,40 & 0,32 & 98,39 & 1,88 & 4,06 \\
\hline $\mathrm{Ca}+\mathrm{Mg}$ & $\mathrm{cmol}_{\mathrm{c}} \mathrm{kg}^{-1}$ & 0,50 & 0,17 & 1,64 & 0,29 & 58,59 & 2,54 & 9,11 \\
\hline $\mathrm{K}$ & $\mathrm{cmol}_{\mathrm{c}} \mathrm{kg}^{-1}$ & 0,03 & 0,01 & 0,08 & 0,02 & 47,98 & 1,57 & 2,88 \\
\hline $\mathrm{Na}$ & $\mathrm{cmol}_{\mathrm{c}} \mathrm{kg}^{-1}$ & 0,03 & 0,01 & 0,08 & 0,02 & 50,14 & 0,85 & 0,26 \\
\hline $\mathrm{Al}$ & $\mathrm{cmol}_{\mathrm{c}} \mathrm{kg}^{-1}$ & 0,59 & 0,05 & 2,01 & 0,45 & 75,72 & 2,00 & 4,08 \\
\hline SB & $\mathrm{cmol}_{\mathrm{c}} \mathrm{kg}^{-1}$ & 0,66 & 0,22 & 3,04 & 0,57 & 85,22 & 3,39 & 13,13 \\
\hline CTC & $\mathrm{cmol}_{\mathrm{c}} \mathrm{kg}^{-1}$ & 2,66 & 1,04 & 6,25 & 1,19 & 44,60 & 1,56 & 2,29 \\
\hline
\end{tabular}

relativamente à aplicação de adubos e corretivos e de preparo do solo. Essas práticas teriam homogeneizado a camada superficial. No presente estudo a cultura é perene, não envolvendo o revolvimento do solo, e, conseqüentemente, o efeito de homogeneização das adubações e correções é menor. Um outro aspecto que pode ser considerado é a menor taxa de lixiviação dos solos aqui estudados, predominantemente LA originados de sedimentos do Barreiras, relativamente aos Latossolos estudados por Corá et al. (2004). O caráter caulinítico, impondo estrutura em blocos de grau fraco e a presença de camadas coesas em subsuperfície, desacelera a lixiviação dos solos originados de sedimentos do Barreiras (Zangrande \& Rezende, 1989).

A análise da relação $\mathrm{C}_{0} /\left(\mathrm{C}_{0}+\mathrm{C}_{1}\right)$, que demonstra o grau de dependência espacial, apresentou todas as variáveis dentro do patamar de moderado a forte. Os graus de dependência alcançados apontam para a eficiência da malha de amostragem utilizada, sem desconsiderar que amostragens mais intensivas podem revelar maior continuidade espacial desses atributos, como comentado por Corá et al. (2004).

\section{Variabilidade espacial do teor de argila e de atributos químicos do solo}

Os parâmetros dos modelos de semivariogramas ajustados para cada variável de estudo foram utilizados para estimar os valores dessas variáveis em locais não amostrados por meio do interpolador geoestatístico krigagem. Com os valores estimados por krigagem foram gerados os mapas de estimativa de ocorrência (de contorno) dos atributos selecionados na área estudada (Figuras 3, 4, 5 e 6).

Para uma gleba de plantio manejada por vários anos, como a da PI de coco estudada, a variabilidade dos atributos químicos do solo é o resultado da 
Quadro 5. Parâmetros estimados dos semivariogramas ajustados (modelo esférico) de algumas variáveis de materiais de solo avaliados ou coletados em microtrincheiras das parcelas experimentais da PIF coco, Frutese, Platô de Neópolis, SE

\begin{tabular}{|c|c|c|c|c|c|c|c|c|}
\hline Variável & Unidade & $\mathrm{Co}^{(1)}$ & $\mathbf{C}_{0}+\mathbf{C}_{1}^{(2)}$ & $\mathrm{Ao}^{(3)}$ & $\mathrm{Co} /\left(\mathrm{C}_{0}+\mathrm{C}_{1}\right)$ & $\mathrm{GDE}^{(4)}$ & $\mathbf{R}^{2}$ & SQR \\
\hline \multicolumn{9}{|c|}{$\begin{array}{l}\mathrm{m} \\
\mathrm{A}, \text { quando este é mais estreito que o limite dado) }\end{array}$} \\
\hline Argila & $\%$ & 6,4600 & 17,890 & 187 & 0,36 & moderado & 0,89 & 12,920 \\
\hline C orgânico & $\mathrm{g} \mathrm{kg}^{-1}$ & 1,7000 & 14,400 & 255 & 0,12 & forte & 0,90 & 6,050 \\
\hline pH água & - & 0,0400 & 0,130 & 228 & 0,31 & moderado & 0,89 & 0,004 \\
\hline $\mathrm{P}$ & $\mathrm{mg} \mathrm{kg}^{-1}$ & 15,2000 & 85,500 & 183 & 0,18 & forte & 0,93 & 49,260 \\
\hline $\mathrm{Ca}+\mathrm{Mg}$ & $\mathrm{cmol}_{\mathrm{c}} \mathrm{kg}^{-1}$ & 0,1200 & 0,450 & 171 & 0,27 & moderado & 0,91 & 0,082 \\
\hline $\mathrm{K}$ & $\mathrm{cmol}_{\mathrm{c}}^{\mathrm{c}} \mathrm{kg}^{-1}$ & 0,0040 & 0,010 & 119 & 0,40 & moderado & 0,88 & 0,087 \\
\hline $\mathrm{Na}$ & $\mathrm{cmol}_{\mathrm{c}} \mathrm{kg}^{-1}$ & 0,0350 & 0,310 & 352 & 0,11 & forte & 0,93 & 0,095 \\
\hline $\mathrm{Al}$ & $\mathrm{cmol}_{\mathrm{c}} \mathrm{kg}^{-1}$ & 0,0004 & 0,002 & 124 & 0,20 & forte & 0,91 & 0,126 \\
\hline $\mathrm{SB}$ & $\mathrm{cmol}_{\mathrm{c}} \mathrm{kg}^{-1}$ & 0,0900 & 0,650 & 216 & 0,14 & forte & 0,90 & 0,092 \\
\hline CTC & $\mathrm{cmol}_{\mathrm{c}}^{\mathrm{c}} \mathrm{kg}^{-1}$ & 0,3500 & 1,100 & 297 & 0,32 & moderado & 0,92 & 0,041 \\
\hline \multicolumn{8}{|c|}{ Amostras de $40-60 \mathrm{~cm}$} & 14,042 \\
\hline C orgânico & $\mathrm{g} \mathrm{kg}^{-1}$ & 0,9000 & 7,500 & 354 & 0,12 & forte & 0,94 & 4,605 \\
\hline pH água & - & 0,0900 & 0,300 & 208 & 0,30 & moderado & 0,95 & 0,031 \\
\hline $\mathrm{P}$ & $\mathrm{mg} \mathrm{kg}^{-1}$ & 0,1100 & 0,400 & 121 & 0,28 & moderado & 0,90 & 0,159 \\
\hline $\mathrm{Ca}+\mathrm{Mg}$ & 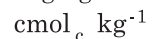 & 0,0200 & 0,110 & 277 & 0,18 & forte & 0,88 & 0,005 \\
\hline $\mathrm{K}$ & $\mathrm{cmol}_{\mathrm{c}}^{\mathrm{c}} \mathrm{kg}^{-1}$ & 0,0200 & 0,100 & 204 & 0,20 & forte & 0,91 & 0,008 \\
\hline $\mathrm{Na}$ & $\mathrm{cmol}_{\mathrm{c}}^{\mathrm{C}} \mathrm{kg}^{-1}$ & 0,0650 & 0,550 & 242 & 0,12 & forte & 0,92 & 0,070 \\
\hline $\mathrm{Al}$ & $\mathrm{cmol}_{\mathrm{c}} \mathrm{kg}^{-1}$ & 0,0020 & 0,011 & 329 & 0,18 & forte & 0,93 & 0,003 \\
\hline $\mathrm{SB}$ & $\mathrm{cmol}_{\mathrm{c}} \mathrm{kg}^{-1}$ & 0,0200 & 0,120 & 235 & 0,17 & forte & 0,89 & 0,012 \\
\hline CTC & $\mathrm{cmol}_{\mathrm{c}} \mathrm{kg}^{-1}$ & 0,1500 & 1,200 & 293 & 0,13 & forte & 0,91 & 0,063 \\
\hline \multicolumn{9}{|c|}{ Amostras de $100-130 \mathrm{~cm}$} \\
\hline C orgânico & $\mathrm{g} \mathrm{kg}^{-1}$ & 0,6000 & 3,500 & 298 & 0,17 & forte & 0,89 & 0,963 \\
\hline pH água & - & 0,0500 & 0,170 & 207 & 0,29 & moderado & 0,91 & 0,009 \\
\hline $\mathrm{P}$ & $\mathrm{mg} \mathrm{kg}^{-1}$ & 0,0100 & 0,085 & 155 & 0,12 & forte & 0,93 & 0,006 \\
\hline $\mathrm{Ca}+\mathrm{Mg}$ & $\mathrm{cmol}_{\mathrm{c}} \mathrm{kg}^{-1}$ & 0,0200 & 0,070 & 181 & 0,29 & moderado & 0,91 & 0,010 \\
\hline $\mathrm{K}$ & $\mathrm{cmol}_{\mathrm{c}} \mathrm{kg}^{-1}$ & 0,0001 & 0,001 & 193 & 0,11 & forte & 0,94 & 0,001 \\
\hline $\mathrm{Na}$ & $\mathrm{cmol}_{\mathrm{c}}^{\mathrm{c}} \mathrm{kg}^{-1}$ & 0,0600 & 0,500 & 209 & 0,12 & for te & 0,88 & 0,027 \\
\hline $\mathrm{Al}$ & $\mathrm{cmol}_{\mathrm{c}} \mathrm{kg}^{-1}$ & 0,0020 & 0,017 & 367 & 0,12 & forte & 0,92 & 0,002 \\
\hline SB & $\mathrm{cmol}_{\mathrm{c}} \mathrm{kg}^{-1}$ & 0,0350 & 0,250 & 210 & 0,14 & forte & 0,91 & 0,210 \\
\hline $\mathrm{CTC}$ & $\mathrm{cmol}_{\mathrm{c}} \mathrm{kg}^{-1}$ & 0,1900 & 1,250 & 304 & 0,15 & forte & 0,93 & 0,068 \\
\hline
\end{tabular}

${ }^{(1)} \mathrm{C}_{0}$ : efeito pepita. ${ }^{(2)} \mathrm{C}_{0}+\mathrm{C}_{1}$ : patamar. ${ }^{(3)} \mathrm{A}_{0}$ : alcance. ${ }^{(4)}$ GDE: grau de dependência espacial. $\mathrm{R}^{2}$ = coeficiente de determinação. $\mathrm{SQR}=$ soma dos quadrados dos resíduos.
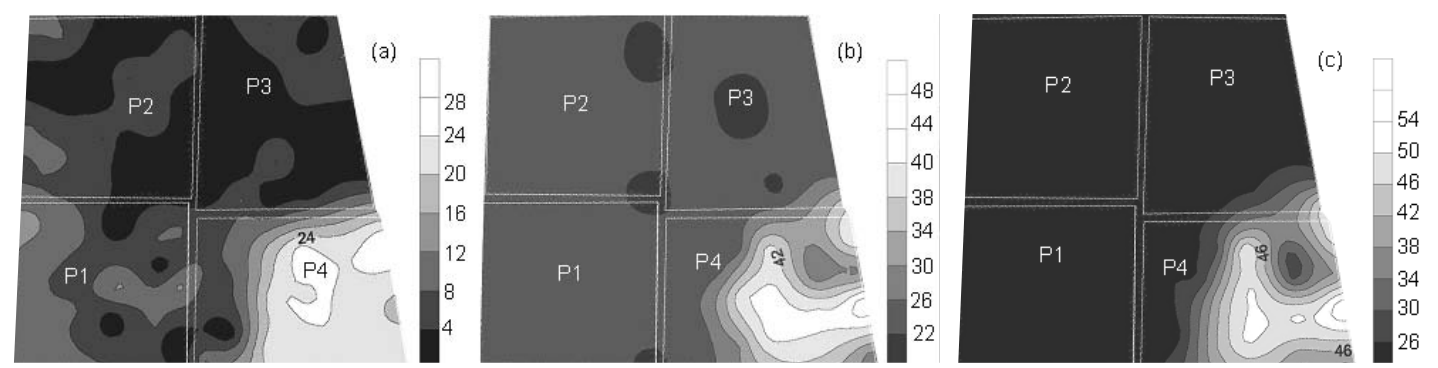

Figura 3. Mapas de contorno do teor de argila de solos das parcelas experimentais da PIF coco, Frutese, Platô de Neópolis, SE, em que P1, P2, P3 e P4 são, respectivamente, as parcelas 1, 2, 3 e 4: (a) \% de argila na profundidade de $0-20 \mathrm{~cm}$; (b) \% de argila na profundidade de $20-40 \mathrm{~cm}$; e (c) \% de argila na profundidade de $100-120 \mathrm{~cm}$.

sobreposição de fatores naturais (material de origem, textura do solo etc.) e de práticas de manejo locais (principalmente adubação mineral), como salientado por Castrignanò et al. (2000) para um campo de produção na Itália.
Os mapas de contorno do teor de argila (Figura 3) detalham as diferenças que o mapa de solos (Figura 1) já apontava, com isolinhas de teor de argila relativamente maiores na parcela 4 , em todas as profundidades. Para alguns outros atributos, as 

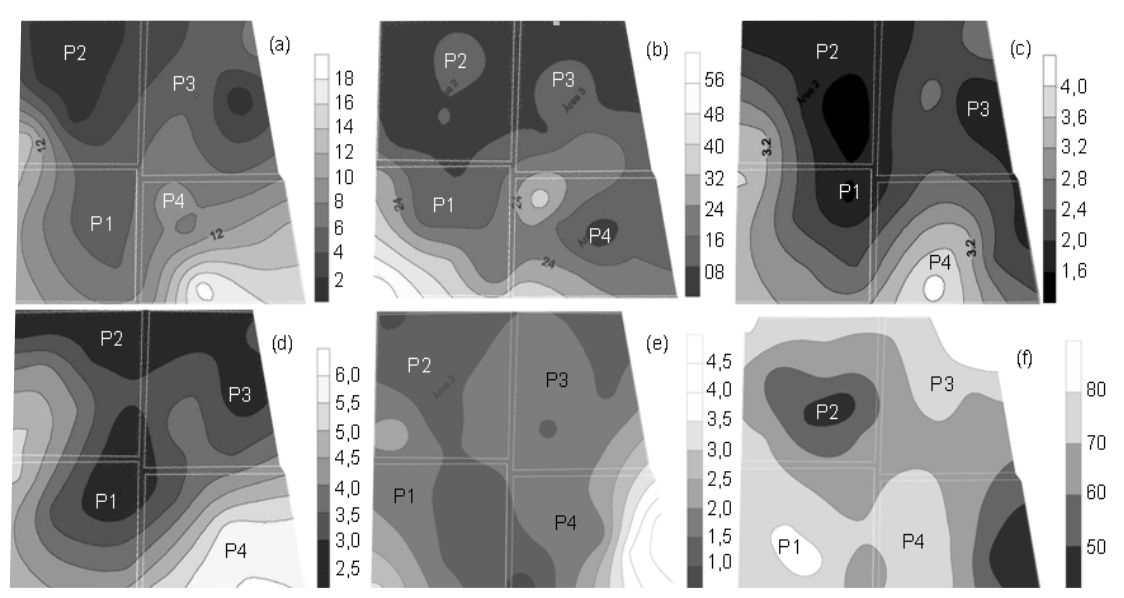

Figura 4. Mapas de contorno de atributos químicos do solo selecionados na profundidade de 0 a $20 \mathrm{~cm}$, das parcelas experimentais da PIF coco, Frutese, Platô de Neópolis, SE, em que P1, P2, P3 e P4 são,

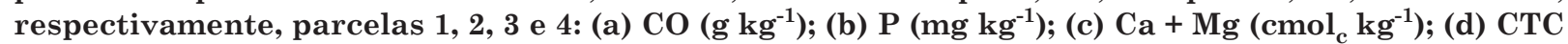
$\left(\mathrm{cmol}_{\mathrm{c}} \mathrm{kg}^{-1}\right)$; (e) relação $\mathrm{Ca} / \mathrm{Mg}$; e (f) V (\%).
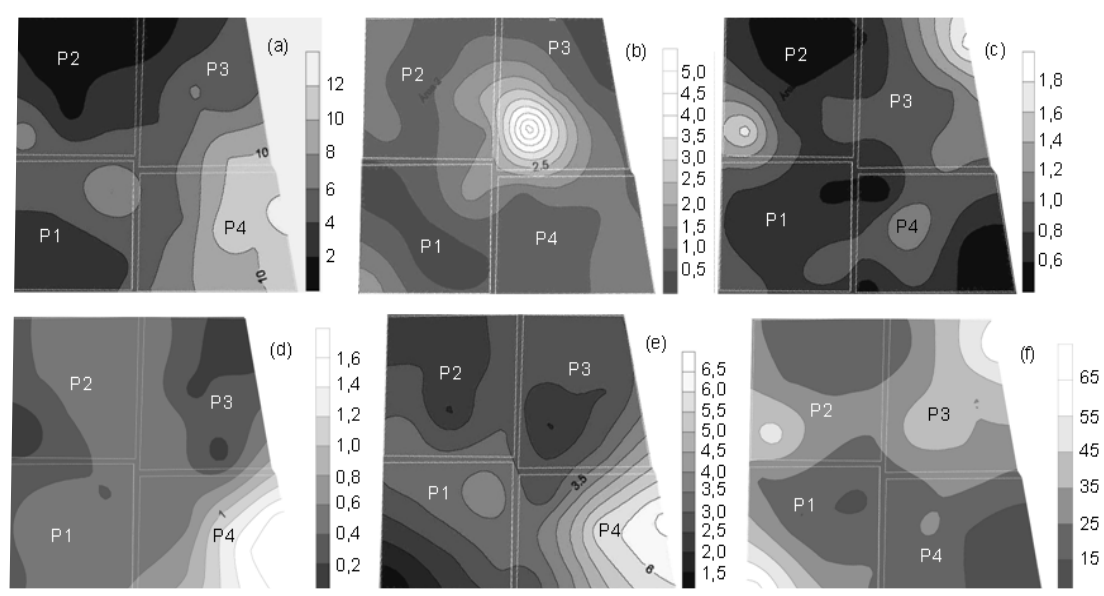

Figura 5. Mapas de contorno de atributos químicos do solo selecionados na profundidade de 40 a $60 \mathrm{~cm}$, das parcelas experimentais da PIF coco, Frutese, Platô de Neópolis, SE, em que P1, P2, P3 e P4 são,

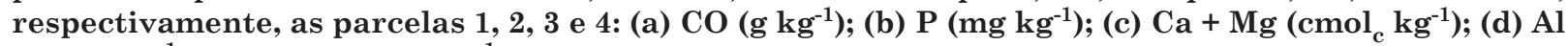
$\left(\mathrm{cmol}_{\mathrm{c}} \mathrm{kg}^{-1}\right)$; (e) CTC $\left(\mathrm{cmol}_{\mathrm{c}} \mathrm{kg}^{-1}\right)$; e (f) V (\%).
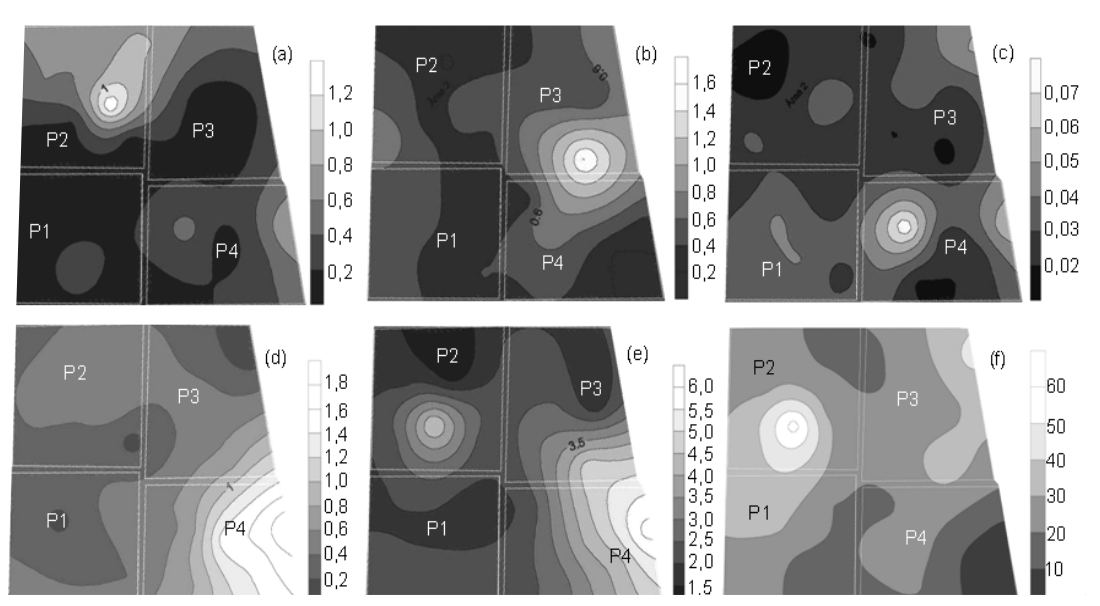

Figura 6. Mapas de contorno de atributos químicos do solo selecionados na profundidade de 100 a $130 \mathrm{~cm}$, das parcelas experimentais da PIF coco, Frutese, Platô de Neópolis, SE, em que P1, P2, P3 e P4 são, respectivamente, as parcelas 1, 2, 3 e 4: (a) $\mathrm{P}\left(\mathrm{mg} \mathrm{kg}^{-1}\right)$; (b) $\mathrm{Ca}+\mathrm{Mg}\left(\mathrm{cmol}_{\mathrm{c}} \mathrm{kg}^{-1}\right) ;(\mathrm{c}) \mathrm{K}\left(\mathrm{cmol}_{\mathrm{c}} \mathrm{kg}^{-1}\right)$; (d) $\mathrm{Al}$ $\left(\mathrm{cmol}_{\mathrm{c}} \mathrm{kg}^{-1}\right)$; (e) CTC $\left(\mathrm{cmol}_{\mathrm{c}} \mathrm{kg}^{-1}\right)$; e (f) V (\%). 
diferenciações influenciadas pela depressão existente na parcela 4 continuam a existir. O CO apresenta isolinhas de maior valor nessa parcela, embora deslocadas para o sul da área. A cor escura dos solos locais, mesmo em profundidade, já apontava para essa possibilidade. A camada de solo superficial está basicamente isenta de $\mathrm{Al}$ (Quadro 4). A correção não é tão eficiente em subsuperfície, com o valor de m ultrapassando $50 \%$ em muitos locais, principalmente na parcela 4, onde a presença de solos mais argilosos e permeabilidade mais baixa deve estar dificultando o efeito das correções. A correção em profundidade é problema mesmo para solos muito permeáveis (Resende et al., 1988), a qual aqui poderia estar sendo acelerada pela presença constante da água de irrigação como um veículo para a lixiviação, ressalvando que os solos locais (originados de sedimentos do Barreiras) apresentam taxas de lixiviação relativamente baixas, se comparadas com Latossolos mais oxídicos - aspecto já abordado anteriormente. O comentado para subsuperfície para o $\mathrm{Al}$ serve de forma inversa para os valores de V. Superficialmente, o V varia muito, embora com valores sempre maiores que $40 \%$. Os resultados em subsuperfície, menores que os superficiais, podem estar limitando a produtividade do coqueiral, uma vez que boa parte da absorção de nutrientes se dá em raízes na profundidade de até $60 \mathrm{~cm}$ (Cintra et al., 1992).

A relação $\mathrm{Ca} / \mathrm{Mg}$ pode ser considerada, em geral, abaixo da esperada. Ela também vai diminuindo em profundidade, padrão que pode ser atribuído à maior absorção do Ca relativamente ao $\mathrm{Mg}$, o que permite sua reposição parcial em superfície (Heck et al., 2002). De toda forma, a adição de produtos mais calcíticos se faz necessária para alargar as relações $\mathrm{Ca} / \mathrm{Mg}$ dos solos locais.

$\mathrm{O} P$ não seguiu um padrão que poderia ser esperado, em razão da maior capacidade de fixação dos solos mais argilosos (Alvarez V. et al., 1999) da parcela 4, parecendo refletir uma adubação desuniforme. Em subsuperfície, os valores são muito baixos e pouca ou nenhuma influência sofrem das adições realizadas.

\section{Definição de unidades de manejo}

A junção das informações dos mapas de solos e de contorno (textura e atributos químicos) permitiu definir duas unidades de manejo para o planejamento da área (Quadro 6). Pode-se considerar que as características das unidades de mapeamento LAdx2 e CXbd apresentam comportamento semelhante e dominam a parcela 4 (unidade de manejo B). A área das outras parcelas (1 a 3) é dominada pela unidade LAdx1 (unidade de manejo A). Essa divisão da área, em duas unidades de manejo, deve ser testada na condução dos cultivos locais.

\section{CONCLUSÕES}

1. Textura e cor ao longo do perfil são os atributos morfológicos de maior eficiência na distinção dos solos e na definição de suas qualidades.

2. A maioria dos atributos estudados apresenta elevado grau de heterogeneidade, principalmente no horizonte mais superficial do solo, como evidenciado pelos valores de alcance e com os valores médios de $\mathrm{P}$, $\mathrm{Ke} \mathrm{Ca}+\mathrm{Mg}$ claramente influenciados por correções e adubações sistemáticas realizadas na área de plantio (coberturas e fertirrigação).

3. Todos os atributos químicos estudados apresentaram grau de dependência espacial moderado a forte.

4. A presença do $\mathrm{Al}$ aumenta em subsuperfície e é maior na parcela 4 , onde a textura mais argilosa e a menor permeabilidade dos solos desaceleram a correção em profundidade. A relação $\mathrm{Ca} / \mathrm{Mg}$ está abaixo da considerada ideal e vai diminuindo em profundidade.

5. O estudo da variabilidade espacial dos atributos químicos e do teor de argila proporcionou a definição de duas unidades de manejo para a área de estudo (unidades A e B), as quais exigem, idealmente, práticas de manejo de água e solo diferenciadas.

Quadro 6. Unidades de manejo, unidades de mapeamento que as compõem, áreas e indicações de práticas de manejo correspondentes das parcelas experimentais da PIF coco, Frutese, Platô de Neópolis, SE

\begin{tabular}{|c|c|c|c|c|}
\hline Unidade de manejo & Unidade de mapeamento & \multicolumn{2}{|c|}{ Área } & Práticas de manejo \\
\hline \multirow[b]{2}{*}{$\mathrm{A}$} & \multirow[b]{2}{*}{ LAdx 1} & ha & $\%$ & \\
\hline & & 27,63 & 76,8 & $\begin{array}{l}<\text { turno de rega; < lâmina de água; < doses de } \mathrm{P} ; \text { e } \\
>\text { parcelamento de } \mathrm{N} \text { e K }\end{array}$ \\
\hline \multirow{3}{*}{$\mathrm{B}$} & LAdx 2 & 6,71 & 18,6 & \multirow{3}{*}{$\begin{array}{l}\text { > turno de rega; > lâmina de água; > doses de P; e } \\
\text { < parcelamento de N e K }\end{array}$} \\
\hline & $\mathrm{CXbd}$ & 1,64 & 4,6 & \\
\hline & Área Total & 35,98 & 100 & \\
\hline
\end{tabular}




\section{LITERATURA CITADA}

ALVAREZ V., V.H.; NOVAIS, R.F.; BARROS, N.F.; CANTARUTTI, R.B. \& LOPES, A.S. Interpretação dos resultados das análises de solos. In: RIBEIRO, A.C.; GUIMARÃES, P.T.G. \& ALVAREZ V., V.H., eds. Recomendações para o uso de corretivos e fertilizantes em Minas Gerais $-5^{\mathrm{a}}$ aproximação. Viçosa, MG, Comissão de Fertilidade do Solo do Estado de Minas Gerais, 1999. p.25-32.

ANDRIGUETO, J.R. \& KOSOSKI, A.R. Marco legal da produção integrada de frutas do Brasil. Brasília, MAPA/ SARC, 2002. 60p.

BERNER, P.G.M.; VIEIRA, S.R.; LIMA, E. \& ANJOS, L.H.C. Variabilidade espacial de propriedades físicas e químicas de um Cambissolo sob dois sistemas de manejo de canade-açúcar. R. Bras. Ci. Solo, 31, 837-844, 2007.

CAMBARDELLA, C.A.; MOORMAN, T.B.; NOVAK, J.M.; PARKIN, T.B.; KARLEN, D.L.; TURCO, R.F. \& KONOPKA, A.E. Field-scale variability of soil properties in central Iowa soils. Soil Sci. Soc. Am. J., 58:1501-1511, 1994.

CASTRIGNANÒ, A.; GIUGLIARINI, L.; RISALITI, R. \& MARTINELLI, N. Study of spatial relationships among some soil physico-chemical properties of a field in central Italy using multivariate geostatistics. Geoderma, 97:39$60,2000$.

CERRI, C.E.P.; BERNOUX, M.; CHAPLOT, V.; VOLKOFF, B.; VICTORIA, R.L.; MELILLO, J.M.; PAUSTIAN, K. \& CERRI, C.C. Assessment of soil property spatial variation in an Amazon pasture: Basis for selecting an agronomic experimental area. Geoderma, 123:51-68, 2004

CINTRA, F.L.D.; LEAL, M.L.S. \& PASSOS, E.E.M. Root system distribution in dwarf coconuts. Oléagineux, 47:225-234, 1992.

CORÁ, J.E.; ARAUJO, A.V.; PEREIRA, G.T. \& BERALDO, J.M.G. Variabilidade espacial de atributos do solo para adoção do sistema de agricultura de precisão na cultura de cana-de-açúcar. R. Bras. Ci. Solo, 28:1013-1021, 2004.

CORÁ, J.E. \& BERALDO, J.M.G. Variabilidade espacial de atributos do solo antes e após calagem e fosfatagem em doses variadas na cultura de cana-de-açúcar. Eng. Agríc., 26:374-387, 2006.

EMPRESA BRASILEIRA DE PESQUISA AGROPECUÁRIA EMBRAPA. Centro de Pesquisas Pedológicas. Levantamento exploratório-reconhecimento de solos do Estado de Sergipe. Recife, Embrapa/Sudene, 1975. 506p. (Boletim Técnico, 36).

EMPRESA BRASILEIRA DE PESQUISA AGROPECUÁRIA EMBRAPA. Serviço Nacional de Levantamento e Conservação de Solos. Manual de métodos de análise de solo. 2.ed. Rio de Janeiro, 1997. 212p.

EMPRESA BRASILEIRA DE PESQUISA AGROPECUÁRIA EMBRAPA. Centro Nacional de Pesquisa de Solos. Sistema brasileiro de classificação de solos. 2ed. Rio de Janeiro, 2006. 306p.

GOLDEN SOFTWARE. Surfer 7.0. Contouring and 3D surface mapping for scientist's engineers. User's guide. New York, 1999. $619 \mathrm{p}$

HECK, R.J.; TIESSEN, H.; SANTOS, M.C.; SALCEDO, I.H. \& ALVES, R.J.T. Chemical changes in Argisols under irrigated grape production in the central São Francisco river valley, Brazil. R. Bras. Ci. Solo, 26:191-202, 2002.
KER, J.C. Latossolos do Brasil: Uma revisão. Geonomos, 5:1740, 1998.

MEHRA, O.P. \& JACKSON, M.L. Iron oxide removal from soils and clays by a dithionite-citrate system buffered with sodium bicarbonate. In: NATIONAL CONFERENCE ON CLAYS AND CLAYS MINERALS, 7., Washington, 1958. Proceedings. New York, 1960. p.317-327.

MILLER, R.W. \& DONAHUE, R.L. Soils: An introduction to soils and plant growth. 6.ed. Englewood Cliffs, Prentice Hall, 1992. 768p.

RESENDE, M.; CURI, N.; REZENDE, S.B. \& CORRÊA, G.F. Pedologia: Base para distinção de ambientes. 4.ed. Viçosa, MG, NEPUT, 2002. 338p.

RESENDE, M.; CURI, N. \& SANTANA, D.P. Pedologia e fertilidade do solo: Interações e aplicações. Piracicaba, MEC/ESAL/POTAFÓS, 1988. 83p.

ROBERTSON, G.P. GS+: Geoestatistics for the environmental sciencies - GS+ User's Guide. Plainwell, Gamma Desing Software, 1998. 152p.

ROQUE, C.G.; CENTURION, J.F.; PEREIRA, G.T.; BEUTLER, A.N.; FREDDI, O.S. \& ANDRIO, I. Variabilidade espacial de atributos químicos em Argissolo Vermelho-Amarelo cultivado com seringueira. R. Ci. Agro-Amb., 3:26-45, 2005 .

SANTOS, R.D.; LEMOS, R.C.; SANTOS, H.G.; KER, J.C. \& ANJOS, L.H.C. Manual de descrição e coleta de solo no campo. 5.ed. Viçosa, MG; Sociedade Brasileira de Ciência do Solo, 2005. 100p.

SERGIPE. Secretaria da Agricultura, Abastecimento e Irrigação - SAGRI. Estudo de viabilidade técnicaeconômica e social do projeto Platô de Neópolis. Estudos básicos - Estudo hidroclimatológico e hidrogeológico. Aracaju, Concremat-Geohidro-Class, 1992. Tomo III, v.1. $93 p$.

SILVA, F.M.; SOUZA, Z.M.; FIGUEIREDO, C.A.P.; MARQUES, J.J. \& MACHADO, R.V. Variabilidade espacial de atributos químicos e de produtividade na cultura do café. Ci. Rural, 37:401-407, 2007.

SOUZA, L.S.; COGO, N.P. \& VIEIRA, S.R. Variabilidade de propriedades físicas e químicas do solo em um pomar cítrico. R. Bras. Ci. Solo, 21:367-372, 1997.

THOMPSON, S.K. Sampling. New York, Wiley-Interscience, 1992. 343p.

TRANGMAR, B.B.; YOST, R.S. \& UEHARA, G. Application of geostatistics to spatial studies of soil properties. Adv. Agron., 38:45-93, 1985.

VIEIRA, S.R. Geoestatística em estudos de variabilidade espacial do solo. In: NOVAIS, R.F.; ALVAREZ V., V.H. \& SCHAEFER, C.E.G.R., eds. Tópicos em ciência do solo. Viçosa, MG, Sociedade Brasileira de Ciência do Solo, 2000. v.1. p.1-54

VIEIRA, S.R.; HATFIELD, J.L.; NIELSEN, D.R. \& BIGGAR, J.W. Geoestatiscal theory and application to variability of some agronomical properties. Hilgardia, 51:1-75, 1983.

ZANGRANDE, M.B. \& REZENDE, S.B. Características de um Podzólico Vermelho-Amarelo abrúptico dos platôs litorâneos do norte do Espírito Santo. R. Ceres, 36:147172,1989 